\section{BMJ Open Respiratory Research}

\title{
One time a day mometasone/indacaterol fixed-dose combination versus two times a day fluticasone/salmeterol in patients with inadequately controlled asthma: pooled analysis from PALLADIUM and IRIDIUM studies
}

Kenneth Chapman, ${ }^{1}$ Richard van Zyl-Smit, ${ }^{2}$ Jorge Maspero, ${ }^{3}$ Huib A M Kerstjens, ${ }^{4}$ Yasuhiro Gon, ${ }^{5}$ Motoi Hosoe, ${ }^{6}$ Ana-Maria Tanase, ${ }^{6}$ Abhijit Pethe, ${ }^{7} \mathrm{Xu} \mathrm{Shu},{ }^{7}$ Peter D'Andrea (D) ${ }^{7}$

To cite: Chapman $\mathrm{K}$, van Zyl-Smit R, Maspero J, et al. One time a day mometasone/ indacaterol fixed-dose combination versus two times a day fluticasone/ salmeterol in patients with inadequately controlled asthma: pooled analysis from PALLADIUM and IRIDIUM studies. BMJ Open Resp Res 2021;8:e000819. doi:10.1136/ bmjresp-2020-000819

- Additional supplemental material is published online only. To view, please visit the journal online (http://dx.doi. org/10.1136/bmjresp-2020000819).

Received 28 October 2020 Accepted 11 July 2021
Check for updates

(C) Author(s) (or their employer(s)) 2021. Re-use permitted under CC BY-NC. No commercial re-use. See rights and permissions. Published by BMJ.

For numbered affiliations see end of article.

Correspondence to Dr Kenneth Chapman; ken.chapman.airways@gmail. com

\section{ABSTRACT}

Background Despite currently available standard-ofcare inhaled corticosteroid (ICS)/long-acting $\beta_{2}$-agonist therapies, a substantial proportion of patients with asthma remain inadequately controlled. This pooled analysis evaluated efficacy and safety of mometasone furoate/indacaterol acetate (MF/IND) versus fluticasone propionate/salmeterol xinafoate (FLU/SAL) in patients with inadequately controlled asthma.

Methods This analysis included patients from PALLADIUM (NCT02554786) and IRIDIUM (NCT02571777) studies who received high-dose MF/IND $(320 / 150 \mu \mathrm{g})$ or medium-dose MF/IND $(160 / 150 \mu \mathrm{g})$ one time a day or high-dose FLU/SAL $(500 / 50 \mu \mathrm{g})$ two times a day for 52 weeks. Reduction in asthma exacerbations, improvement in lung function, asthma control, and safety were evaluated for 52 weeks.

Results In total, 3154 patients (high-dose MF/IND, $\mathrm{n}=1054$; medium-dose MF/IND, $\mathrm{n}=1044$; high-dose FLU/SAL, $n=1056$ ) were included. High-dose MF/ IND showed $26 \%, 22 \%$ and $19 \%$ reductions in rate of severe, moderate or severe, and all (mild, moderate and severe) exacerbations versus high-dose FLU/SAL, respectively, over 52 weeks (all, $\mathrm{p}<0.05$ ). High-dose MF/IND improved trough $\mathrm{FEV}_{1}$ versus high-dose FLU/ SAL at weeks $26(\Delta, 43 \mathrm{~mL}, \mathrm{p}=0.001)$ and $52(\Delta, 51$ $\mathrm{mL}, \mathrm{p}<0.001)$. Reductions in asthma exacerbation rate and improvement in trough $\mathrm{FEV}_{1}$ with medium-dose MF/IND were comparable with high-dose FLU/SAL over 52 weeks. All treatments improved Asthma Control Questionnaire-7 score from baseline to 52 weeks with no difference between treatments. Safety was comparable between high-dose MF/IND and high-dose FLU/SAL.

Conclusions One time a day, single-inhaler, high-dose MF/IND reduced asthma exacerbations and improved lung function versus two times a day, high-dose FLU/ SAL in patients with inadequately controlled asthma. Similarly, improved outcomes were seen with one time a day, medium-dose MF/IND and two times a day, highdose FLU/SAL, but at a lower ICS dose.

\section{Key messages}

What is the efficacy and safety of one time a day, single-inhaler mometasone furoate/indacaterol acetate (MF/IND) versus two times a day fluticasone propionate/salmeterol xinafoate (FLU/SAL) in patients with inadequately controlled asthma?

One time a day, single-inhaler, mometasone furoate/ indacaterol acetate (MF/IND) at both doses (highand medium-dose) reduced asthma exacerbations and improved lung function versus two times a day, high-dose fluticasone propionate/salmeterol xinafoate (FLU/SAL) in patients with inadequately controlled asthma

We report the results from the pooled analysis of the efficacy and safety of high-dose MF/IND $(320 / 150 \mu \mathrm{g})$ or medium-dose MF/IND $(160 / 150 \mu \mathrm{g})$ one time a day or high-dose FLU/SAL $(500 / 50 \mu \mathrm{g})$ two times a day for 52 weeks in patients with inadequately controlled asthma from the PALLADIUM and IRIDIUM studies.

\section{INTRODUCTION}

The Global Initiative for Asthma (GINA) guidelines recommend the combination of a medium- or high-dose inhaled corticosteroid (ICS) with a long-acting $\beta_{2}$-agonist (LABA) as the preferred controller treatment in patients with asthma uncontrolled on ICS alone or lowdose ICS/LABA combination. ${ }^{1}$ Compared with ICS monotherapy (higher or similar doses), ICS/LABA combination therapy reduces asthma exacerbations, improves lung function and demonstrates better asthma control in adults with persistent asthma. ${ }^{2}$

One time a day ICS/LABA dosing regimens have been associated with better efficacy 
(asthma exacerbations), increased adherence and a lower risk of discontinuation compared with two times a day regimens, which might lead to improved asthma control. ${ }^{34}$ The standard-of-care ICS/LABA fixed-dose combinations (FDCs) fluticasone propionate/salmeterol xinafoate (FLU/SAL), budesonide/formoterol (BUD/FORM), fluticasone furoate/vilanterol (FF/VI) and beclomethasone dipropionate/formoterol (BDP/ FORM) have been shown to be safe and effective in the management of asthma. ${ }^{5-8}$ However, a substantial proportion of patients (approximately 30\%-50\%) remain uncontrolled on currently available ICS/LABA therapies. ${ }^{910}$ Patients with poor asthma control may have increased healthcare resource utilisation and higher rates of morbidity and mortality compared with patients with controlled asthma. ${ }^{9}$ The ICS mometasone furoate (MF) and the LABA indacaterol acetate (IND) have been formulated as FDC therapy (MF/IND) one time a day delivered via Breezhaler ${ }^{\circledR}$ for maintenance treatment of patients with asthma. Two phase III pivotal studies (PALLADIUM and IRIDIUM) compared the efficacy and safety of high- and medium- dose MF/IND with highdose FLU/SAL, among other comparisons, in patients with inadequately controlled asthma, and that supported the recent approvals of MF/IND and MF/IND/glycopyrronium bromide (GLY). ${ }^{11} 12$

This prespecified pooled analysis of the PALLADIUM $^{11}$ and IRIDIUM ${ }^{12}$ studies assessed the efficacy and safety of high-dose MF/IND (320/150 $\mu \mathrm{g})$ one time a day (via Breezhaler ${ }^{\circledR}$ ) versus the standard-of-care treatment high-dose FLU/SAL $(500 / 50 \mu g)$ two times a day (via Diskus ${ }^{\circledR}$ ) in patients with inadequetely controlled asthma. In addition, we also report the post-hoc analysis results from the efficacy comparison of medium-dose MF/IND $(160 / 150 \mu \mathrm{g})$ one time a day (via Breezhaler ${ }^{\circledR}$ ) versus the high-dose FLU/SAL $(500 / 50 \mu g)$ two times a day (via Diskus ${ }^{\circledR}$ ) in these patients. Not all endpoints that are assessed between high-dose MF/IND and high-dose FLU/SAL, were analysed between medium-dose MF/IND and high-dose FLU/SAL, since some endpoints were not prespecified for the medium-dose MF/IND comparison to high-dose FLU/SAL.

\section{METHODS}

Study design

We present pooled analysis of data from the PALLADIUM $(\text { NCT02554786) })^{11}$ and IRIDIUM (NCT02571777) ${ }^{12}$ studies. Details of the study designs and methodologies have been published elsewhere. ${ }^{11} 12$

In brief, the PALLADIUM study was a 52-week, multicentre, double-blind, triple-dummy, parallel-group, active-controlled study that randomised (1:1:1:1:1) patients with inadequately controlled asthma (despite treatment with medium- or high-dose ICS or low-dose ICS/LABA) to receive high-dose MF/IND $(320 / 150 \mu \mathrm{g})$ or medium-dose MF/IND $(160 / 150 \mu \mathrm{g})$ one time a day

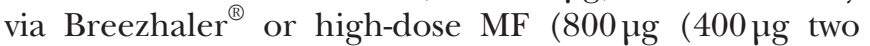

times a day) ) or medium-dose MF ( $400 \mu \mathrm{g})$ one time a day via Twisthaler ${ }^{\circledR}$ or high-dose FLU/SAL $(500 / 50 \mu \mathrm{g})$ two times a day via Diskus ${ }^{\circledR}$. The IRIDIUM study was a 52-week, double-blind, double-dummy, parallel-group, active-controlled study that randomised (1:1:1:1:1) patients with inadequately controlled asthma (despite treatment with medium- or high-dose ICS/LABA) to receive high-dose MF/IND/GLY $(160 / 150 / 50 \mu \mathrm{g})$ or medium-dose $\mathrm{MF} / \mathrm{IND} / \mathrm{GLY}(80 / 150 / 50 \mu \mathrm{g})$ or highdose MF/IND (320/150 $\mu \mathrm{g})$ or medium-dose MF/IND $(160 / 150 \mu \mathrm{g})$ one time a day via Breezhaler ${ }^{\circledR}$ or highdose FLU/SAL $(500 / 50 \mu \mathrm{g})$ two times a day via Diskus ${ }^{\circledR}$.

The current analysis pooled the data from patients from the PALLADIUM and IRIDIUM studies who received high-dose MF/IND (320/150 $\mu$ g) or medium-dose MF/ IND $(160 / 150 \mu \mathrm{g})$ one time a day via Breezhaler ${ }^{\circledR}$ or highdose FLU/SAL $(500 / 50 \mu \mathrm{g})$ two times a day via Diskus ${ }^{\circledR}$ for 52 weeks. $^{1112}$

\section{Patient and public involvement}

Patients or the public were not involved in the design, conduct or interpretation of this pooled analysis.

\section{Patients}

This pooled analysis included patients who had received the same dose of high-dose MF/IND, medium-dose MF/ IND and high-dose FLU/SAL in the PALLADIUM and IRIDIUM studies. ${ }^{11} 12$ Patient inclusion and exclusion criteria have been published previously. ${ }^{11} 12$

In brief, patients included in this analysis from the PALLADIUM study were aged $\geq 12$ and $\leq 75$ years with a documented diagnosis of asthma and prebronchodilator forced expiratory volume in $1 \mathrm{~s}\left(\mathrm{FEV}_{1}\right)$ of $\geq 50 \%$ and $<85 \%$ of predicted. Symptomatic patients with an Asthma Control Questionnaire-7 (ACQ-7) score $\geq 1.5$ and receiving medium- or high-dose ICS monotherapy or low-dose ICS/LABA for $\geq 3$ months at a stable dose for $\geq 1$ month prior to screening were included. ${ }^{11}$ Patients from the IRIDIUM study included in this analysis were aged $\geq 18$ and $\leq 75$ years with a diagnosis of asthma and receiving medium- or high-dose ICS/LABA for $\geq 3$ months and at a stable dose for $\geq 1$ month prior to screening. Patients needed to have a prebronchodilator $\mathrm{FEV}_{1}<80 \%$ of predicted and be symptomatic with an ACQ-7 score $\geq 1.5$ at screening. Patients needed to have a documented history of $\geq 1$ asthma exacerbations that required systemic corticosteroid (SCS) treatment, emergency room (ER) visit, or hospitalisation in the 12 months prior to screening. ${ }^{12}$

In both studies, key exclusion criteria were: (1) an asthma attack/exacerbation requiring SCS or hospitalisation within 6 weeks of screening; (2) an ER visit within 6 weeks of screening; (3) a history of chronic lung disease other than asthma; (4) inhaled tobacco products within 6 months before screening, or $>10$ pack-years smoking history; (5) clinically significant comorbidity or laboratory abnormality at the run-in visit. 


\section{Outcomes}

As both studies used the same doses of MF/IND and FLU/SAL in similar proportions, this allowed pooling for various endpoints between the interventions in this analysis. This pooled analysis compared the following efficacy parameters with high-dose $\mathrm{MF} / \mathrm{IND}$ one time a day and medium-dose MF/IND one time a day versus high-dose FLU/SAL two times a day: annualised rate of asthma exacerbations (severe, moderate or severe, and all (mild, moderate, severe)) over 52 weeks; improvement in trough $\mathrm{FEV}_{1}$ at Weeks 26 and 52; mean change in ACQ-7 score $^{1314}$ from baseline at weeks 4, 12, 26 and 52; and proportion of patients with improvement of ACQ-7 score $\geq 0.5$ (minimal clinically important difference (MCID) $)^{1516}$ and achieving absolute ACQ-7 score $<0.75$ from baseline at weeks 4, 12, 26 and 52. Severe exacerbations was defined as an aggravation of asthma symptoms that required SCS for at least three consecutive days, need for an ER visit, hospitalisation, or death due to asthma. The definition of moderate and mild asthma exacerbations is presented in supplementary material (online supplemental table S1).

In addition, the prespecified analysis determined several comparisons between high-dose MF/IND and high-dose FLU/SAL. These include: (1) time-to-first asthma exacerbation over 52 weeks; (2) change in morning and evening peak expiratory flow (PEF) from baseline to 52 weeks at 4-week intervals; (3) asthma symptom endpoints based on eDiary and rescue medication endpoints at 4-week intervals through to 52 weeks; (4) recording of adverse events (AEs, safety analysis) over 52 weeks. Asthma symptom endpoints based on eDiary include mean daytime asthma symptom score, the total daily symptom score, days with no daytime symptoms, nights with no night-time awakenings, mornings with no symptoms on awakening, and asthma symptom-free days. Rescue medication endpoints include mean daytime/night-time, and daily number of puffs of rescue medication, and rescue medicationfree days.

Table 1 Summary of baseline demographics and clinical characteristics (pooled population from PALLADIUM and IRIDIUM studies; full analysis set)

\begin{tabular}{|c|c|c|c|}
\hline & $\begin{array}{l}\text { High-dose MF/IND } \\
(320 / 150 \mu g) \text { one time a } \\
\text { day }(n=1054)\end{array}$ & $\begin{array}{l}\text { Medium-dose MF/IND } \\
(160 / 150 \mu \mathrm{g}) \text { one time a } \\
\text { day }(\mathrm{n}=1044)\end{array}$ & $\begin{array}{l}\text { High-dose FLU/SAL } \\
(500 / 50 \mu \mathrm{g}) \text { two times a } \\
\text { day }(\mathrm{n}=1056)\end{array}$ \\
\hline & $\begin{array}{l}\text { PALLADIUM }(n=443) \\
\text { IRIDIUM }(n=611)\end{array}$ & $\begin{array}{l}\text { PALLADIUM }(n=437) \\
\text { IRIDIUM }(n=607)\end{array}$ & $\begin{array}{l}\text { PALLADIUM }(n=444) \\
\text { IRIDIUM }(n=612)\end{array}$ \\
\hline Age, years & $49.9 \pm 13.74$ & $50.0 \pm 13.85$ & $51.2 \pm 13.39$ \\
\hline \multicolumn{4}{|l|}{ Gender, n (\%) } \\
\hline Female & $638(60.5)$ & $621(59.5)$ & $666(63.1)$ \\
\hline Duration of asthma, years ${ }^{*}$ & $15.9 \pm 13.87$ & $16.6 \pm 14.61$ & $16.8 \pm 14.56$ \\
\hline Baseline ACQ-7 score† & $2.4 \pm 0.56$ & $2.4 \pm 0.52$ & $2.4 \pm 0.53$ \\
\hline \multicolumn{4}{|c|}{ Number of asthma exacerbations in the 12 months prior to screening, $\mathrm{n}(\%)$} \\
\hline 0 & 305 (28.9) & $308(29.5)$ & $300(28.4)$ \\
\hline 1 & $608(57.7)$ & $566(54.2)$ & $600(56.8)$ \\
\hline$>1$ & $141(13.4)$ & $170(16.3)$ & $156(14.8)$ \\
\hline $\begin{array}{l}\text { Pre-bronchodilator } \mathrm{FEV}_{1} \text { (\% predicted) } \\
\text { prior to run-in visit }\end{array}$ & $59.0 \pm 12.98$ & $59.4 \pm 12.97$ & $59.6 \pm 12.72$ \\
\hline $\begin{array}{l}\text { FEV }_{1} \text { reversibility (\%) prior to run-in } \\
\text { visit } \neq\end{array}$ & $25.9 \pm 17.62$ & $25.6 \pm 17.22$ & $26.0 \pm 18.92$ \\
\hline \multicolumn{4}{|l|}{ Prior asthma treatment; $\mathrm{n}(\%) \S$} \\
\hline Medium-/high-dose ICS/LABA & $634(59.6)$ & $623(59.0)$ & $629(59.1)$ \\
\hline Low-dose ICS/LABA & $316(29.7)$ & $299(28.3)$ & $302(28.4)$ \\
\hline ICS monotherapy & $107(10.1)$ & $119(11.3)$ & $123(11.6)$ \\
\hline
\end{tabular}

Data are presented as mean \pm SD unless otherwise specified.

*Duration of asthma was calculated from the start date of asthma recorded on the eCRF until the date of screening.

†The baseline ACQ-7 score was reported at screening, or if missing, at the last visit from run-in.

$\ddagger F E V_{1}$ reversibility was calculated as increase of $\mathrm{FEV}_{1}$ value after inhalation of bronchodilator $(400 \mu \mathrm{g} \mathrm{salbutamol} / 360 \mu \mathrm{g}$ albuterol, or equivalent dose) relative to $\mathrm{FEV}_{1}$ value before inhalation of bronchodilator.

$\S$ The summary of baseline medication is based on randomised set population included in the PALLADIUM and IRIDIUM studies (high-dose MF/IND, $n=1063$; medium-dose MF/IND, $n=1056$; high-dose FLU/SAL, $n=1064$ ). All other parameters included are based on full analysis set from both the studies.

ACQ, Asthma Control Questionnaire; FEV , forced expiratory volume in 1s; FLU/SAL, fluticasone propionate/salmeterol xinafoate; ICS, inhaled corticosteroid; LABA, long-acting $\beta_{2}$-agonist; MF/IND, mometasone furoate/indacaterol acetate; $n$, number of patients. 


\section{Statistical analysis}

All the efficacy analyses were conducted in patients included in the full analysis set (FAS). The FAS included all patients who were assigned a randomisation number and received at least one dose of study medication. Annualised rates of asthma exacerbations were analysed using a generalised linear model assuming the negative binomial distribution. The description of models are presented in the supplementary material (online supplemental table S1). Time-to-event variables were analysed using a Cox regression model stratified by study. Trough $\mathrm{FEV}_{1}$ and ACQ-7 score were analysed using a mixed model for repeated measures (MMRM). The proportion of patients who achieved an improvement of at least 0.5 in ACQ-7 (ie, a decrease of ACQ-7 score of at least 0.5 from baseline) at weeks 4, 12, 26 and 52 were analysed using the logistic regression model via the generalised estimating equations. The same logistic regression model was used for analysing the proportion of patients with absolute score less than 0.75 at weeks 4, 12, 26 and 52. The PEF was analysed using ANalysis of COVAriance (ANCOVA) and similar MMRM as used for trough $\mathrm{FEV}_{1}$, with baseline $\mathrm{FEV}_{1}$ value replaced with the proper baseline PEF. Asthma symptom endpoints based on eDiary and rescue medication endpoints were analysed using ANCOVA and MMRM on changes from baseline similar to the analysis of PEF with the proper baseline values as a covariate. The safety assessments were performed in patients who received at least a single dose of study medication (safety analysis set). MedDRA V.22.0 has been used for the reporting of AEs. The number and percentage of patients who reported AEs were summarised. All analyses were performed using SAS V.9.4.

\section{RESULTS}

\section{Baseline and clinical characteristics}

In total, 3154 patients (high-dose MF/IND, n=1054; medium-dose MF/IND, n=1044; high-dose FLU/SAL, $\mathrm{n}=1056$ ) were included in this pooled analysis. The baseline and clinical characteristics were comparable between the groups (table 1). The mean age of patients was approximately 50 years, with more female $(59.5 \%-$ $63.1 \%$ ) than male patients included across the three groups.

\section{Asthma exacerbations}

High-dose MF/IND one time a day showed a $26 \%$ reduction in the rate of severe exacerbations, $22 \%$ reduction in the rate of moderate or severe exacerbations, and $19 \%$ reduction in rate of all exacerbations compared with high-dose FLU/SAL two times a day (all, $\mathrm{p}<0.05$ ) (figure 1A). Medium-dose MF/IND one time a day was comparable with high-dose FLU/SAL two times a day in reducing the rate of moderate or severe exacerbations and severe exacerbations (both, $\mathrm{p}>0.05$ ), while achieving a considerably lower rate of all asthma exacerbation types $(16 \%, \mathrm{p}=0.024)$ versus high-dose FLU/SAL two times a day over the 52 week treatment period (figure 1B). Based on the time to first asthma exacerbation analysis, highdose $\mathrm{MF} / \mathrm{IND}$ one time a day showed a $27 \%$ reduction (HR $0.73,95 \%$ CI 0.60 to $0.89, \mathrm{p}=0.002$ ), $24 \%$ reduction (HR $0.76,95 \%$ CI 0.65 to $0.90, \mathrm{p}=0.001$ ), and $21 \%$ reduction (HR $0.79,95 \%$ CI 0.68 to $0.90, \mathrm{p}<0.001$ ) in the risk of severe, moderate or severe, and all exacerbation categories, respectively, compared with high-dose FLU/SAL two times a day.

\section{Lung function}

High-dose MF/IND one time a day showed greater improvement in trough $\mathrm{FEV}_{1}$ compared with high-dose FLU/SAL two times a day at weeks $26(\mathrm{p}=0.001)$ and 52 $(\mathrm{p}<0.001)$ (figure 2A). Medium-dose MF/IND one time a day was comparable with high-dose FLU/SAL two times a day at improving trough $\mathrm{FEV}_{1}$ at weeks $26(\mathrm{p}=0.034)$ and $52(\mathrm{p}=0.154)$ (figure 2B).

High-dose MF/IND one time a day showed improvements in morning and evening PEF versus high-dose
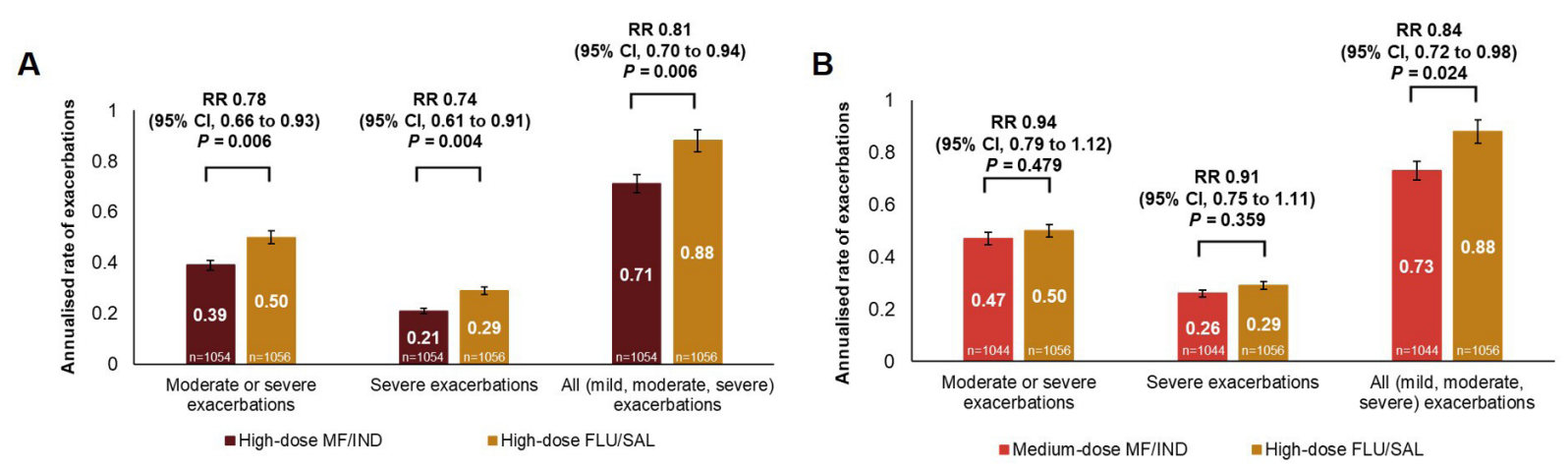

Figure 1 Annualised rate of asthma exacerbations over 52 weeks with: (A) high-dose MF/IND one time a day and (B) medium-dose MF/IND one time a day compared with high-dose FLU/SAL two times a day in patients with inadequately controlled asthma. Data presented as annualised rate $(95 \% \mathrm{Cl})$; error bars represent $\mathrm{Cl}$ values. Participants received highdose MF/IND (320/150 $\mu \mathrm{g})$ one time a day; or medium-dose MF/IND (160/150 $\mu \mathrm{g})$ one time a day; or high-dose FLU/SAL $(500 / 50 \mu \mathrm{g})$ two times a day. $\mathrm{n}$, number of patients analysed. FLU/SAL, fluticasone propionate/salmeterol xinafoate; MF/IND, mometasone furoate/indacaterol acetate; RR, rate ratio. 
A

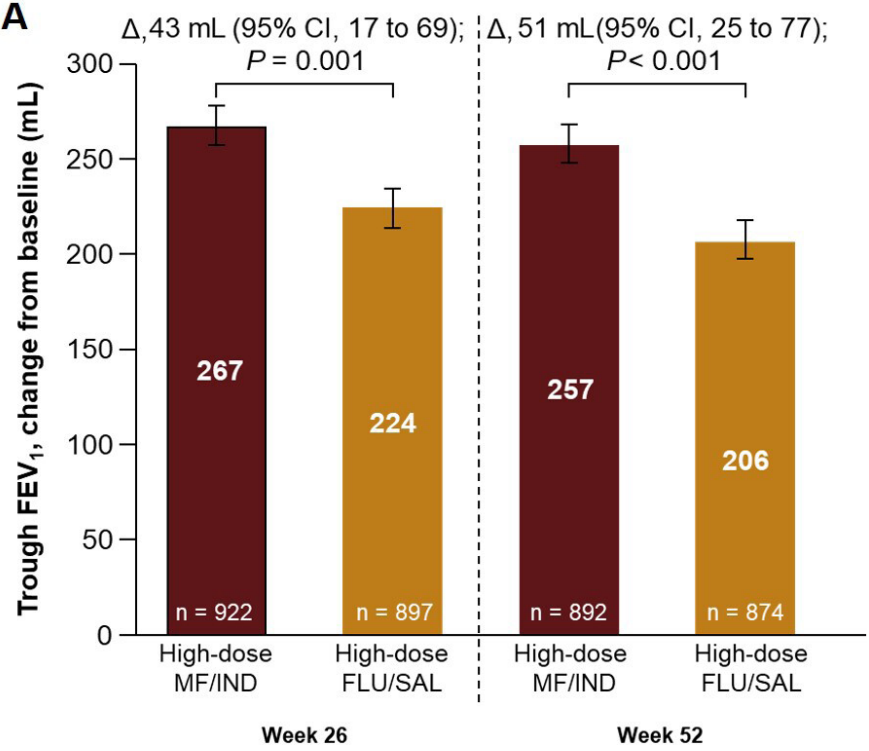

B

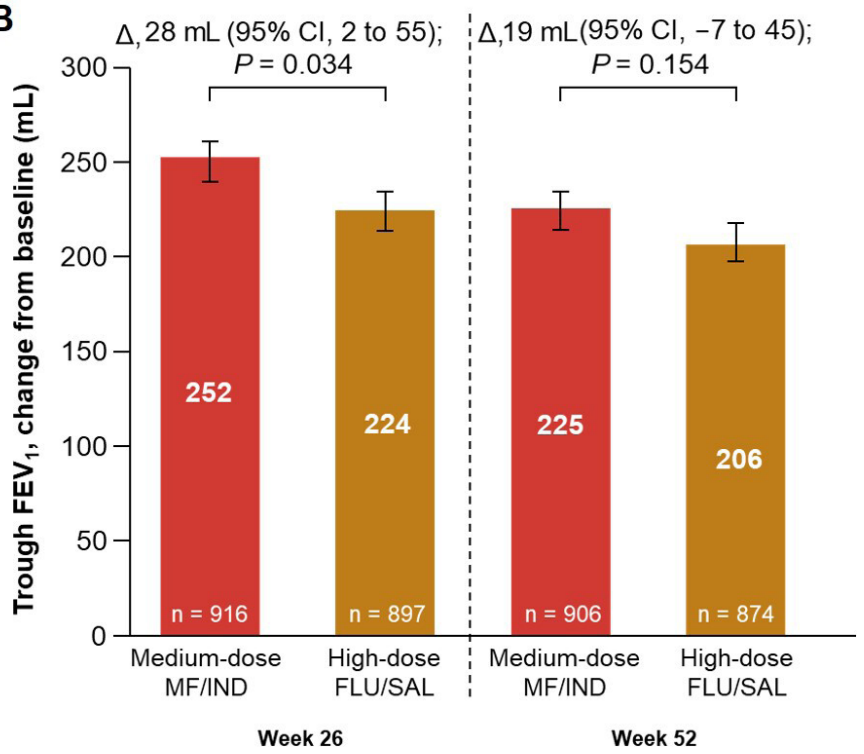

Figure 2 Improvements in trough FEV at weeks 26 and 52 with (A) high-dose MF/IND one time a day and (B) medium-dose MF/IND one time a day compared with high-dose FLU/SAL two times a day in patients with inadequately controlled asthma. Data presented as LS mean \pm SE, error bars represent SE values. Participants received high-dose MF/IND $(320 / 150 \mu g)$ one time a day; or medium-dose MF/IND $(160 / 150 \mu \mathrm{g})$ one time a day; or high-dose FLU/SAL $(500 / 50 \mu \mathrm{g})$ two times a day. $\mathrm{n}$, number of patients analysed. $\triangle$, LS mean treatment difference; FEV , forced expiratory volume in $1 \mathrm{~s}$; FLU/SAL, fluticasone propionate/salmeterol xinafoate; LS, least square; MF/IND, mometasone furoate/indacaterol acetate.

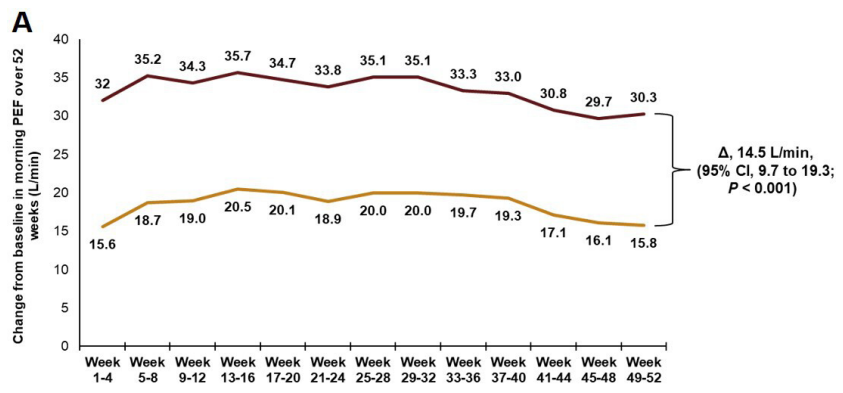

FLU/SAL two times a day in each 4-week interval from baseline to 52 weeks $(\mathrm{p}<0.001)$ (figure 3$)$. The least square mean treatment difference $(\Delta)$ in morning PEF $(\mathrm{L} / \mathrm{min})$ from baseline with high-dose $\mathrm{MF} / \mathrm{IND}$ one time a day was greater compared with high-dose FLU/ SAL two times a day at week $52(\Delta, 14.5,95 \%$ CI 9.7 to 19.3, $\mathrm{p}<0.001$ ) (figure $3 \mathrm{~A})$. The change $(\Delta)$ in evening PEF from baseline to week 52 was $11 \mathrm{~L} / \mathrm{min}(95 \%$ CI 6.2 to $15.7, \mathrm{p}<0.001$ ) with high-dose MF/IND one time a day versus high-dose FLU/SAL two times a day (figure 3B).

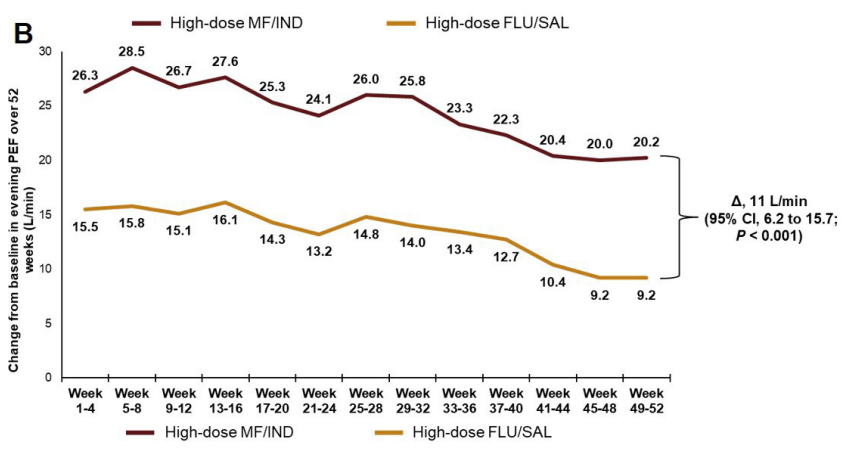

\section{Asthma control}

All treatments improved the ACQ-7 score from baseline to 52 weeks (figure 4). High-dose MF/IND one time a day produced a greater reduction in ACQ-7 score from baseline to week $4(\mathrm{p}=0.001)$, week $12(\mathrm{p}=0.003)$ and week $26(\mathrm{p}=0.004)$, and comparably at week $52(\mathrm{p}=0.197)$ versus high-dose FLU/SAL two times a day (figure 4A). Medium-dose MF/IND one time a day resulted in comparable improvements in ACQ-7 score versus high-dose FLU/SAL two times a day at weeks 4, 12, 26 and 52. More than $70 \%$ of patients achieved at least once MCID (0.5 points) improvement in ACQ-7 score in all treatment arms after 26 weeks. At week 4, more patients achieved at least one MCID in ACQ-7 score in high-dose MF/ IND one time a day group than high-dose FLU/SAL two times a day group $(64.4 \%$ vs $57.3 \%$, OR, $1.31,95 \% \mathrm{CI}$, 1.09 to $1.58, \mathrm{p}=0.004)$. A comparable number of patients in the high-dose MF/IND and medium-dose MF/IND arms achieved the MCID in ACQ-7 score compared 

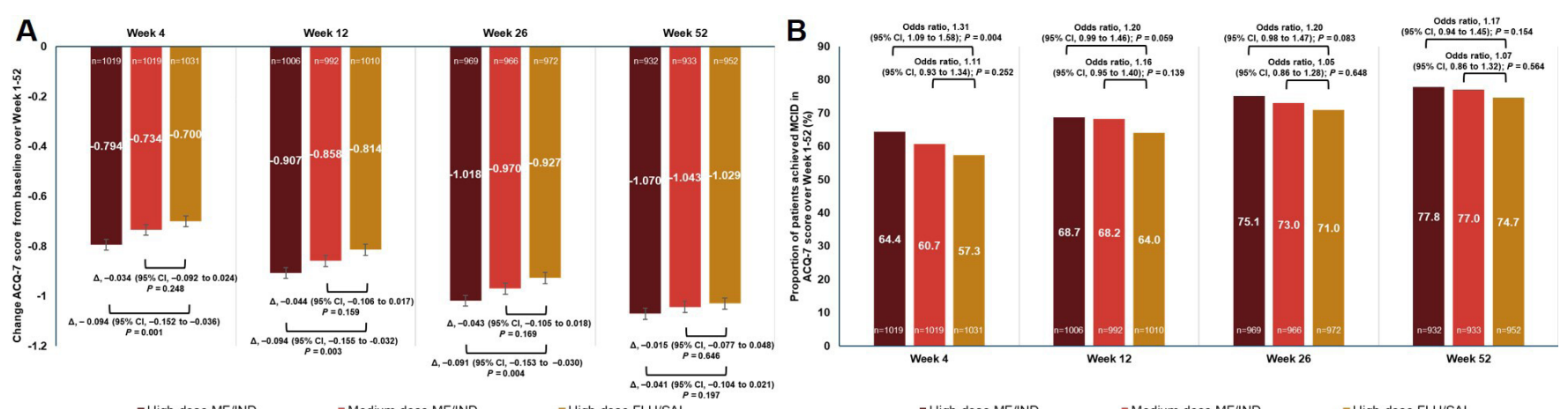

- High-dose MF/ND

$$
\text { C }
$$

C

$=$ High-dose FLU/SAL

- High-dose MF/IND

- Medium-dose MFIND

=High-dose FLU/SAL

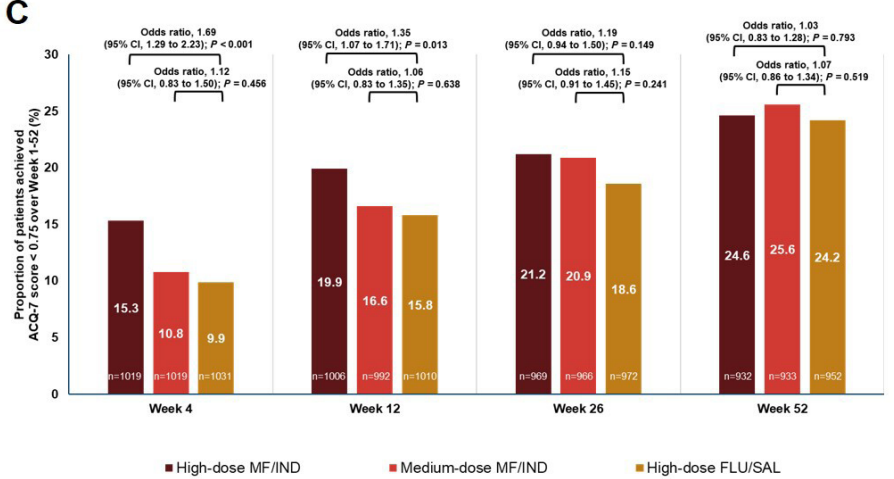

Figure 4 (A) Treatment difference in ACQ-7 score. (B) Proportion of patients achieving MCID in ACQ-7 score, and (C) proportion of patients achieving ACQ-7 score $<0.75$, from baseline with high-dose MF/IND one time a day and medium-dose $\mathrm{MF} / \mathrm{IND}$ one time a day versus high-dose FLU/SAL two times a day through weeks 1-52. Data presented as LS mean $\pm S E$, error bars represent SE values. Participants received high-dose MF/IND (320/150 $\mu$ g) one time a day; or medium-dose MF/IND (160/150 $\mu \mathrm{g})$ one time a day; or high-dose FLU/SAL (500/50 $\mu \mathrm{g})$ two times a day. $\mathrm{n}$, number of patients analysed. $\Delta$, LS mean treatment difference; ACQ, Asthma Control Questionnaire; FLU/SAL, fluticasone propionate/salmeterol xinafoate; LS, least square; MCID, minimal clinical treatment difference; MF/IND, mometasone furoate/indacaterol acetate.

with high-dose FLU/SAL up to week 52 (figure 4B). At weeks 4 and 12, more patients receiving high-dose MF/ IND one time a day achieved ACQ-7 score $<0.75$ from baseline compared with high-dose FLU/SAL two times a day $(15.3 \%$ vs $9.9 \%$, OR, $1.69,95 \%$ CI, 1.29 to 2.23 , $\mathrm{p}<0.001$; and $19.9 \%$ vs $15.8 \%$, OR, $1.35,95 \%$ CI, 1.07 to $1.71, \mathrm{p}=0.013$, respectively) (figure $4 \mathrm{C}$ ). No noticeable differences were observed for all other comparisons and time points.

\section{Other efficacy endpoints}

Both high-dose MF/IND one time a day and high-dose FLU/SAL two times a day provided improvements in asthma symptom endpoints over 52 weeks (online supplemental table S2). Mean total daily symptom score $(\Delta$, $-0.12,95 \%$ CI -0.23 to $-0.02, \mathrm{p}=0.022$ ) and percentage of mornings with no symptoms on awakening $(\Delta, 5.4 \%$, $95 \%$ CI $2.0 \%$ to $8.8 \%, \mathrm{p}=0.002$ ) were improved with high-dose MF/IND one time a day compared with highdose FLU/SAL two times a day over 52 weeks of treatment. Improvement in mean daytime asthma symptom score, percentage of days with no daytime symptoms and percentage of nights with no night-time awakenings were comparable between both the treatment groups. Patients receiving high-dose MF/IND one time a day reported more asthma symptom-free days compared with patients receiving high-dose FLU/SAL two times a day over 52 weeks $(\Delta, 3.6 \%, 95 \% \mathrm{CI}, 0.0 \%$ to $7.2 \%, \mathrm{p}=0.048)$. The reduction in number of puffs of rescue medication in daily, daytime, and night-time use were comparable between high-dose MF/IND one time a day and high-dose FLU/SAL two times a day at week 52 (online supplemental table S3). Patients receiving high-dose MF/ IND one time a day reported considerably more rescue medication-free days compared with high-dose FLU/SAL two times a day after 52 weeks of treatment period $(\Delta$, $3.2 \%, 95 \%$ CI $0.1 \%$ to $6.3 \%, p=0.044)$.

\section{Safety}

The incidence of AEs was comparable in patients receiving high-dose MF/IND one time a day and highdose FLU/SAL two times a day over 52 weeks of treatment. The AEs by preferred term, occurring in $>2 \%$ of patients in any treatment group are presented in table 2. In total, $740(70.1 \%)$ and $777(73.2 \%)$ patients reported at least one $\mathrm{AE}$ in high-dose $\mathrm{MF} / \mathrm{IND}$ one time a day and high-dose FLU/SAL two times a day groups, respectively. Asthma (reported as an asthma exacerbation) was the most frequent $\mathrm{AE}$ reported in both groups followed by nasopharyngitis, upper respiratory tract infection, bronchitis and viral upper respiratory tract infection (table 2). All other AEs were reported in $<5 \%$ patients in 
Table 2 Patients with AEs (>2.0\%) by preferred term and SAEs occurring in high-dose MF/IND one time a day and high-dose FLU/SAL two times a day groups

\begin{tabular}{|c|c|c|}
\hline Preferred term & $\begin{array}{l}\text { High-dose MF/ } \\
\text { IND } \\
(320 / 150 \mu \mathrm{g}) \\
\text { one time a day } \\
\mathrm{n}=1056\end{array}$ & $\begin{array}{l}\text { High-dose FLU/ } \\
\text { SAL }(500 / 50 \mu g) \\
\text { two times a day } \\
n=1062\end{array}$ \\
\hline \multicolumn{3}{|l|}{ AEs, n (\%) } \\
\hline $\begin{array}{l}\text { Patients with at least } \\
\text { one } A E\end{array}$ & $740(70.1)$ & 777 (73.2) \\
\hline Asthma & 369 (34.9) & $446(42.0)$ \\
\hline Nasopharyngitis & $123(11.6)$ & $130(12.2)$ \\
\hline $\begin{array}{l}\text { Upper respiratory tract } \\
\text { infection }\end{array}$ & $74(7.0)$ & $90(8.5)$ \\
\hline Headache & $50(4.7)$ & 47 (4.4) \\
\hline Bronchitis & 66 (6.3) & $72(6.8)$ \\
\hline Back pain & $27(2.6)$ & $22(2.1)$ \\
\hline $\begin{array}{l}\text { Respiratory tract } \\
\text { infection viral }\end{array}$ & $21(2.0)$ & $35(3.3)$ \\
\hline Influenza & 35 (3.3) & $40(3.8)$ \\
\hline Hypertension & 24 (2.3) & $29(2.7)$ \\
\hline Pharyngitis & $30(2.8)$ & $34(3.2)$ \\
\hline Rhinitis & $27(2.6)$ & $20(1.9)$ \\
\hline $\begin{array}{l}\text { Viral upper respiratory } \\
\text { tract infection }\end{array}$ & $45(4.3)$ & $68(6.4)$ \\
\hline Cough & $19(1.8)$ & $23(2.2)$ \\
\hline Rhinitis allergic & $14(1.3)$ & $27(2.5)$ \\
\hline $\begin{array}{l}\text { Upper respiratory tract } \\
\text { infection bacterial }\end{array}$ & $32(3.0)$ & $37(3.5)$ \\
\hline $\begin{array}{l}\text { Lower respiratory tract } \\
\text { infection }\end{array}$ & $17(1.6)$ & $30(2.8)$ \\
\hline $\begin{array}{l}\text { Patient with at least one } \\
\text { AE leading to permanent } \\
\text { discontinuation of study } \\
\text { drug, } n(\%)\end{array}$ & $27(2.6)$ & $32(3.0)$ \\
\hline \multicolumn{3}{|l|}{ SAEs, n (\%) } \\
\hline $\begin{array}{l}\text { Patients with at least } \\
\text { one SAE }\end{array}$ & $73(6.9)$ & $60(5.6)$ \\
\hline Asthma & $15(1.4)$ & $11(1.0)$ \\
\hline $\begin{array}{l}\text { Acute myocardial } \\
\text { infarction }\end{array}$ & $3(0.3)$ & $2(0.2)$ \\
\hline Pneumonia & $2(0.2)$ & $5(0.5)$ \\
\hline $\begin{array}{l}\text { Lower respiratory tract } \\
\text { infection }\end{array}$ & $3(0.3)$ & $2(0.2)$ \\
\hline Atrial fibrillation & $1(0.1)$ & $2(0.2)$ \\
\hline Peritonitis & $1(0.1)$ & $3(0.3)$ \\
\hline Death, n (\%) & $4(0.4)$ & 0 \\
\hline
\end{tabular}

A patient with multiple AEs with the same preferred term is counted only once for that preferred term. Only AEs reported while on study drug or within 7 days of the last dose (within 30 days for SAEs) are included.

$\mathrm{AE}$, adverse event; FLU/SAL, fluticasone propionate/salmeterol xinafoate; MF/IND, mometasone furoate/indacaterol acetate; $n$, number of patients; SAE, serious adverse event. both treatment groups over the 52-week period. The AEs by preferred term, occurring in at least $1.0 \%$ of patients in any treatment group are presented in supplementary material (online supplemental table S4). Cardiovascular AEs (hypertension (24, 2.3\%; 29, 2.7\%), and increased blood pressure $(3,0.3 \% ; 3,0.3 \%))$ were comparable with high-dose MF/IND one time a day versus high-dose FLU/ SAL two times a day. The incidence of serious adverse events (SAEs) was comparable between the groups (highdose MF/IND one time a day, 73 patients $(6.9 \%)$; highdose FLU/SAL two times a day, 60 patients $(5.6 \%)$ ), with asthma being the most often reported SAE in both groups (table 2). In total, $27(2.6 \%)$ and $32(3.0 \%)$ patients in high-dose MF/IND one time a day and high-dose FLU/ SAL two times a day groups, respectively, had at least one $\mathrm{AE}$ that led to permanent discontinuation (table 2). Four deaths were reported in the high-dose MF/IND group (one train accident, one lymphoma, one sudden death, and one sudden death in a patient with multiple, severe cardiovascular comorbidities); no death was considered to be study drug related.

\section{DISCUSSION}

This analysis of pooled data from the PALLADIUM and IRIDIUM studies investigated asthma exacerbations, lung function and asthma control outcomes with highdose MF/IND and medium-dose MF/IND one time a day versus high-dose FLU/SAL two times a day in patients with inadequately controlled asthma on low-to-high dose ICS/LABA or ICS monotherapy (GINA steps 3 and 4 patients). High-dose MF/IND one time a day reduced asthma exacerbations and improved lung function to a greater extent than high-dose FLU/SAL two times a day. The safety outcomes with high-dose MF/IND one time a day were comparable with high-dose FLU/SAL two times a day. Medium-dose MF/IND one time a day produced comparable improvements in lung function and asthma control, and numerically greater reductions in rate of all exacerbations, and comparable reductions in moderate or severe and severe exacerbations versus high-dose FLU/SAL two times a day, in patients with inadequately controlled asthma at a reduced steroid burden.

There is evidence that ICS/LABA one time a day regimen might be associated with better adherence and persistence compared with a two times a day regimen with similar or improved efficacy. ${ }^{34}$ However, the majority of ICS/LABA combinations, except FF/VI, are administered two times a day. ${ }^{17} 18$ In this analysis, both doses of MF/ IND were administered one time a day, in the evening; and FLU/SAL given two times a day, in the morning and evening. We note that our study design, requiring that patients inhale from both active and placebo devices in both two times a day and one time a day schedules, would have prevented any adherence advantage contributing to the greater efficacy of the one time a day regimen. To investigate whether there is an added advantage in 
clinical practice would require a quite different 'real world' study.

In this analysis, the reduction in annualised rate of severe, moderate or severe and all asthma exacerbations was greater, and time-to-first asthma exacerbation was longer with high-dose MF/IND than high-dose FLU/SAL over the 52-week treatment period. Medium-dose MF/ IND achieved comparable reductions in severe and moderate or severe exacerbations, and numerically greater reductions in all exacerbations compared with high-dose FLU/SAL. In a post-hoc analysis of the Salford Lung Study, FF/VI (100-200/25 $\mu \mathrm{g})$ achieved a $20 \%$ reduction in the annual rate of severe exacerbations compared with FLU/SAL in adults with symptomatic asthma. ${ }^{19}$ However, in the published studies evaluating BUD/FORM, FF/VI, BDP/FORM, no significant difference in terms of rate of asthma exacerbations and timeto-first exacerbations were observed between ICS/LABA FDCs versus FLU/SAL in patients with inadequately controlled asthma. ${ }^{20-22}$

High-dose MF/IND achieved greater improvements in trough $\mathrm{FEV}_{1}$ when compared with high-dose FLU/SAL at weeks $26(43 \mathrm{~mL}, \mathrm{p}=0.001)$ and $52(51 \mathrm{~mL}, \mathrm{p}<0.001)$. Medium-dose MF/IND showed comparable improvements in trough $\mathrm{FEV}_{1}$ versus high-dose FLU/SAL at weeks 26 and 52. In a double-blind randomised controlled trial (RCT), similar results for trough $\mathrm{FEV}_{1}(19 \mathrm{~mL})$ reported with $\mathrm{FF} /$ VI $(100 / 25 \mu \mathrm{g}$ one time a day) compared with mediumdose FLU/SAL (250/50 $\mu$ g two times a day) at week 24 in patients with persistent asthma already controlled on ICS/ $\mathrm{LABA}^{23}$ In this pooled analysis, the $\mathrm{FEV}_{1}$ and PEF values (morning and evening) were improved with high-dose MF/ IND compared with high-dose FLU/SAL.

ACQ-7 scores were improved from baseline in all treatment groups. In this analysis, $75 \%$ of patients on highdose MF/IND, $73 \%$ on medium-dose MF/IND, and $71 \%$ on high-dose FLU/SAL achieved at least one MCID in ACQ-7 score at week 26. In this analysis, the proportion of patients who achieved MCID for ACQ-7 score in FLU/ SAL group increased in each time interval in parallel with patients who received MF/IND. This result is also in alignment with the published literature; for example, Bernstein et al, reported similar achievement of MCID in ACQ-7 score in patients who continued FLU/SAL (250/50 $\mu$ g two times a day) and MF/FORM (200/10 $\mu \mathrm{g}$ two times a day) over a treatment period up to 12 weeks. ${ }^{24}$ All asthma symptom endpoints (eDiary) and rescue medication use were improved with all treatments.

The safety results are consistent with the published studies that compared the available FDCs of ICS/LABA with FLU/SAL. ${ }^{19-21}$ In this analysis, the reported frequency of SAEs was low and the incidence was comparable between treatment groups. Four deaths were reported, and all were not drug related as per the investigator.

There are several limitations to this analysis. This is a prespecified analysis for outcomes between highdose MF/IND one time a day and high-dose FLU/SAL two times a day (same ICS level), and post-hoc analysis for medium-dose MF/IND one time a day versus highdose FLU/SAL two times a day (lower ICS level). Not all endpoints that were evaluated between high-dose MF/IND one time a day versus high-dose FLU/SAL two times a day were evaluated between medium-dose MF/ IND one time a day versus high-dose FLU/SAL two times a day. In addition, high-dose MF/IND one time a day and medium-dose MF/IND one time a day was not directly compared as this was not included in the prespecified analysis, and the studies were not powered for this analysis.

\section{CONCLUSION}

To our knowledge, this is the first pooled analysis from RCTs to show the consistent efficacy benefits of any ICS/LABA versus high-dose FLU/SAL in terms of reductions in asthma exacerbation and improvement in lung function. This prespecified pooled analysis of the Phase III PALLADIUM and IRIDIUM studies indicates that at a similar dose of ICS, one time a day, highdose MF/IND (320/150 $\mu \mathrm{g})$ reduced asthma exacerbations and improved lung function to a greater extent than two times a day, high-dose FLU/SAL $(500 / 50 \mu \mathrm{g})$ in patients with inadequately controlled asthma. At a lower dose of ICS, one time a day, medium-dose MF/ IND $(160 / 150 \mu \mathrm{g})$ produced a comparable reduction in rates of asthma exacerbation and improvement in lung function similar to that seen with two times a day, high-dose FLU/SAL $(500 / 50 \mu \mathrm{g})$. Both one time a day, high-dose MF/IND and two times a day, high-dose FLU/SAL were well tolerated with acceptable safety profiles. These result provide evidence supporting $\mathrm{MF} / \mathrm{IND}$ as a potential treatment option in patients with asthma.

\section{Ethics and disssemination}

All the data generated in this pooled analysis were based on previously published studies (PALLADIUM and IRIDIUM), which were approved by the Independent Ethics Committee or Institutional Review Boards and were conducted in accordance with the International Conference on Harmonisation Guidelines for Good Clinical Practice and the Declaration of Helsinki. All patients provided written informed consent for inclusion in the studies.

\section{Author affiliations}

${ }^{1}$ Division of Respiratory Medicine, Department of Medicine, University of Toronto, Toronto, Ontario, Canada

${ }^{2}$ Division of Pulmonology and UCT Lung Institute, Department of Medicine, University of Cape Town, Cape Town, South Africa

${ }^{3}$ Allergy and Respiratory Research Unit, Fundación Centro Investigacion de Enfermedades Alergicas y Respiratorias, Buenos Aires, Argentina

${ }^{4}$ Department of Pulmonology, University of Groningen, University Medical Center Groningen, and Groningen Research Institute for Asthma and COPD, Groningen, The Netherlands

${ }^{5}$ Division of Respiratory Medicine, Department of Internal Medicine, Nihon University School of Medicine, Tokyo, Japan

${ }^{6}$ Novartis Pharma AG, Basel, Switzerland 
${ }^{7}$ Novartis Pharmaceuticals Corporation, East Hanover, New Jersey, USA

Acknowledgements Under the direction of authors, Rabi Narayan Panigrahy and lan Wright (professional medical writers; Novartis) assisted in the preparation of this article in accordance with the third edition of Good Publication Practice (GPP3) guidelines (http://www.ismpp.org/gpp3)

Contributors PALLADIUM study was designed by A-MT and PD. Data were acquired by RvZ-S and YG, and analysed by AP and XS. RvZ-S is the principal investigator for PALLADIUM study. IRIDIUM study was designed by HAMK, A-MT, and PD. MH contributed to conduct of the study. Data were acquired by HAMK, JM, $\mathrm{KC}$ and RvZ-S, and analysed by AP and XS. HAMK is the principal investigator for IRIDIUM study. The authors contributed to the preparation of the manuscript draft, along with critical review and approval of manuscript for submission to the journal. All authors contributed to the intellectual content of the manuscript and approved it for publication.

Funding Both PALLADIUM and IRIDIUM studies were funded by Novartis Pharmaceuticals Corporation, East Hanover, NJ, United States.

Competing interests Authors received no compensation related to development of the manuscript. KC reports grants and personal fees from AstraZeneca, Boehringer Ingelheim, GlaxoSmithKline, Grifols, Novartis, Regeneron, Sanofi, and Takeda, grants from Vertex, and personal fees from CSL Behring, Inhibrx, and Kamada, all outside of the submitted work. RvZ-S reports receiving personal fees from Aspen-GlaxoSmithKline, Pfizer, Roche, AstraZeneca, Novartis, Merck Sharp \& Dohme, and Cipla, outside of the submitted work. JM reports grants and personal fees from Novartis, during the conduct of the study, grants and personal fees from Sanofi, and personal fees from AstraZeneca and ImmunoTek. HAMK reports grants and fees for consultancy or advisory board participation from Novartis, during the conduct of the study; and grants and fees for consultancy or advisory board participation from GlaxoSmithKline and Boehringer Ingelheim, and a grant from Chiesi, outside of the submitted work. All were paid to his institution. YG reports receiving personal fees from Novartis, GlaxoSmithKline, AstraZeneca, and Boehringer Ingelheim, outside the submitted work. MH and A-MT are employees of Novartis Pharma. AP, XS, and PD are employees of Novartis Pharmaceuticals.

Patient consent for publication Not required.

Provenance and peer review Not commissioned; externally peer reviewed.

Data availability statement Data are available upon reasonable request. All data relevant to the study are included in the article or uploaded as supplementary information. Novartis is committed to sharing access to patient-level data and supporting documents from eligible studies with qualified external researchers. These requests are reviewed and approved by an independent review panel on the basis of scientific merit. All data provided are anonymised to respect the privacy of patients who have participated in the trial in line with applicable laws and regulations.

Supplemental material This content has been supplied by the author(s). It has not been vetted by BMJ Publishing Group Limited (BMJ) and may not have been peer-reviewed. Any opinions or recommendations discussed are solely those of the author(s) and are not endorsed by BMJ. BMJ disclaims all liability and responsibility arising from any reliance placed on the content. Where the content includes any translated material, BMJ does not warrant the accuracy and reliability of the translations (including but not limited to local regulations, clinical guidelines, terminology, drug names and drug dosages), and is not responsible for any error and/or omissions arising from translation and adaptation or otherwise.

Open access This is an open access article distributed in accordance with the Creative Commons Attribution Non Commercial (CC BY-NC 4.0) license, which permits others to distribute, remix, adapt, build upon this work non-commercially, and license their derivative works on different terms, provided the original work is properly cited, appropriate credit is given, any changes made indicated, and the use is non-commercial. See: http://creativecommons.org/licenses/by-nc/4.0/.

ORCID iD

Peter D’Andrea http://orcid.org/0000-0001-9831-1568

\section{REFERENCES}

1 Global Initiative for Asthma. Global strategy for asthma management and prevention, 2019. Available: http://www.ginasthma.org/ginareports/ [Accessed 25 Jun 2020].

2 Canadian Agency for Drugs and Technologies in Health (CADTH). Long-acting beta(2)-agonist and inhaled corticosteroid combination therapy for adult persistent asthma: systematic review of clinical outcomes and economic evaluation. CADTH Technol Overv 2010;1:e0120 http://www.ncbi.nlm.nih.gov/pubmed/22977410

3 Averell $\mathrm{CM}$, Stanford RH, Laliberté $\mathrm{F}$, et al. Medication adherence in patients with asthma using once-daily versus twice-daily ICS/ LABAs. J Asthma 2021;58:102-11.

4 Dal Negro RW, Bonadiman L, Turco P. Fluticasone furoate/Vilanterol 92/22 $\mu \mathrm{g}$ once-a-day vs Beclomethasone dipropionate/Formoterol 100/6 $\mu$ g b.I.D.: a 12-month comparison of outcomes in mild-tomoderate asthma. Multidiscip Respir Med 2018;13:18.

5 Scichilone N, Braido F, Lavorini F, et al. Routine use of budesonide/ formoterol fixed dose combination in elderly asthmatic patients: practical considerations. Drugs Aging 2017;34:321-30.

6 McKeage K, Keam SJ. Salmeterol/Fluticasone propionate. Drugs 2009;69:1799-828.

7 Huchon G, Magnussen $\mathrm{H}$, Chuchalin A, et al. Lung function and asthma control with beclomethasone and formoterol in a single inhaler. Respir Med 2009;103:41-9.

8 Woodcock A, Vestbo J, Bakerly ND, et al. Effectiveness of fluticasone furoate plus vilanterol on asthma control in clinical practice: an open-label, parallel group, randomised controlled trial. Lancet 2017;390:2247-55.

9 Buhl R, Heaney LG, Loefroth E, et al. One-year follow up of asthmatic patients newly initiated on treatment with medium- or high-dose inhaled corticosteroid-long-acting $\beta_{2}$-agonist in UK primary care settings. Respir Med 2020;162:105859.

10 Schatz M, Meckley LM, Kim M, et al. Asthma exacerbation rates in adults are unchanged over a 5 -year period despite high-intensity therapy. J Allergy Clin Immunol Pract 2014;2:570-4

11 van Zyl-Smit RN, Krüll M, Gessner C, et al. Once-Daily mometasone plus indacaterol versus mometasone or twice-daily fluticasone plus salmeterol in patients with inadequately controlled asthma (PALLADIUM): a randomised, double-blind, triple-dummy, controlled phase 3 study. Lancet Respir Med 2020;8:987-99.

12 Kerstjens HAM, Maspero J, Chapman KR, et al. Once-Daily, single-inhaler mometasone-indacaterol-glycopyrronium versus mometasone-indacaterol or twice-daily fluticasone-salmeterol in patients with inadequately controlled asthma (IRIDIUM): a randomised, double-blind, controlled phase 3 study. Lancet Respir Med 2020;8:1000-12.

13 Juniper EF, Bousquet J, Abetz L, et al. Identifying 'well-controlled' and 'not well-controlled' asthma using the Asthma Control Questionnaire. Respir Med 2006;100:616-21.

14 Juniper EF, O'Byrne PM, Guyatt GH, et al. Development and validation of a questionnaire to measure asthma control. Eur Respir $J$ 1999; 14:902-7.

15 Jia CE, Zhang HP, Lv Y, et al. The asthma control test and asthma control questionnaire for assessing asthma control: systematic review and meta-analysis. J Allergy Clin Immunol 2013;131:695-703.

16 Barnes PJ, Casale TB, Dahl R, et al. The asthma control questionnaire as a clinical trial endpoint: past experience and recommendations for future use. Allergy 2014;69:1119-40.

17 Seong G, Lee J, Song J. Comparison of clinical efficacy between morning and evening dosing of once-daily inhaled corticosteroids in patients with asthma: a systemic review and meta-analysis [Abstract]. Am J Respir Crit Care Med 2018;197:P4833.

18 Kempsford RD, Oliver A, Bal J, et al. The efficacy of once-daily fluticasone furoate/vilanterol in asthma is comparable with morning or evening dosing. Respir Med 2013;107:1873-80.

19 Jacques L, Bakerly ND, New JP, et al. Effectiveness of fluticasone furoate/vilanterol versus fluticasone propionate/salmeterol on asthma control in the Salford lung study. J Asthma 2019;56:748-57.

20 Kuna P. Treatment comparison of Budesonide/Formoterol with Salmeterol/Fluticasone propionate in adults aged $\geq 16$ years with asthma. Clin Drug Investig 2010;30:565-79.

21 Woodcock A, Bleecker ER, Lötvall J, et al. Efficacy and safety of fluticasone furoate/vilanterol compared with fluticasone propionate/ salmeterol combination in adult and adolescent patients with persistent asthma: a randomized trial. Chest 2013;144:1222-9.

22 Papi A, Paggiaro P, Nicolini G, et al. Beclomethasone/formoterol vs fluticasone/salmeterol inhaled combination in moderate to severe asthma. Allergy 2007;62:1182-8.

23 Bernstein D, Andersen L, Forth R, et al. Once-daily fluticasone furoate/vilanterol versus twice-daily fluticasone propionate/ salmeterol in patients with asthma well controlled on ICS/LABA. $J$ Asthma 2018;55:984-93

24 Bernstein DI, Hébert J, Cheema A, et al. Efficacy and onset of action of mometasone furoate/formoterol and fluticasone propionate/ salmeterol combination treatment in subjects with persistent asthma. Allergy Asthma Clin Immunol 2011;7:21-30. 